\title{
C-13 NMR Analysis of Isolated Ethylene Units in Ethylene-Propylene Copolymer
}

\author{
Tetsuo AsaKura, ${ }^{\dagger}$ Yûkô NishiYAma, Yoshiharu DoI, ${ }^{*}$ \\ and Isao ANDO** \\ Department of Polymer Engineering, Faculty of Technology, \\ Tokyo University of Agriculture and Technology, \\ Koganei, Tokyo 184, Japan \\ * Research Laboratory of Resources Utilization, \\ Tokyo Institute of Technology, \\ Nagatsuda-cho, Midori-ku, Yokohama 227, Japan \\ ** Department of Polymer Chemistry, Faculty of Engineering, \\ Tokyo Institute of Technology, \\ Ookayama, Meguro-ku, Tokyo 152, Japan
}

(Received November 17, 1986)

\begin{abstract}
C}$ NMR spectra of isolated ethylene units in $\left[1,2-{ }^{13} \mathrm{C}\right]$ enriched ethylenepropylene copolymer prepared with syndiotactic-specific catalyst were observed. The use of $[1,2-$ ${ }^{13} \mathrm{C}$ ] enriched ethylene units made it possible to determine the fractions of three kinds of the structures, $m E m, m E r, r E r$ where $m$ means meso propylene dyad, $E$ isolated ethylene unit and $r$ racemo propylene dyad in the copolymer. This is based on change in the NMR spectral pattern depending on the relative magnitude between ${ }^{13} \mathrm{C}-{ }^{13} \mathrm{C}$ coupling constant and chemical shift difference.

KEY WORDS ${ }^{13} \mathrm{C}$ NMR / $\left[1,2-{ }^{13} \mathrm{C}\right]$ Ethylene-Propylene Copolymer /

Syndiotactic-Specific Catalyst / Tacticity /
\end{abstract}

C-13 NMR analysis of isolated ethylene units in ethylene-propylene, E-P copolymers gives useful information on the mechanism of stereospecinic polymerization of polypropylene. ${ }^{1-6}$

Zambelli et al. ${ }^{1,4}$ have shown ${ }^{13} \mathrm{C}$ NMR spectra of two typical samples of $\left[1-{ }^{13} \mathrm{C}\right]$ enriched E-P copolymers. The resonances of the isolated ethylene units $\left(\mathrm{C}^{*-} \mathrm{C}^{*}\right)$ exclusively arise from the insertion of the ethylene units between propylene units with the same orientation (structure A) rather than those between two propylene units in head-tail and tail-head orientations (structure B) for the sample prepared in the presence of an isotactic-specific catalyst.

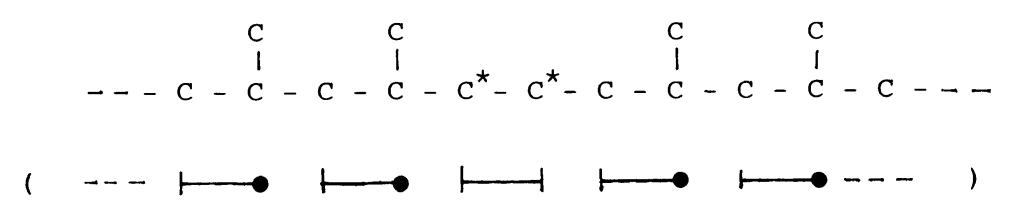

Structure A

\footnotetext{
$\dagger$ To whom requests for reprints should be addressed.
} 


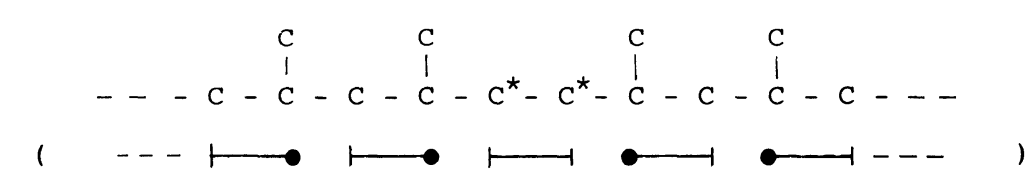

Structure B

$\longmapsto:-\mathrm{CH}_{2}-\underset{\mathrm{CH}_{3}}{\mathrm{CH}}-\stackrel{-}{\longrightarrow} \underset{\mathrm{CH}_{3}}{\mathrm{CH}}-\mathrm{CH}_{2}-\longmapsto:-\mathrm{CH}_{2}-\mathrm{CH}_{2}-$

In contrast, the spectrum of the sample prepared with a syndiotactic-specific catalyst shows resonances for carbons of isolated ethylene units in both structures A and B although the proportion of the latter structure is large. From detailed analysis of these spectra, they concluded that both the regiospecificity and the stereospecificity are controlled by the last units of the growing chain end for syndiotactic-specific catalyst system, but regiospecificity and stereospecificity are unaffected by the ethylene units in the isotactic polymerization. ${ }^{4}$

It seems especially important to analyze the complicated ${ }^{13} \mathrm{C}$ NMR spectrum of the E-P copolymer prepared with syndiotactic-specific catalyst on the basis of rigorous assignment due to the tacticity as pointed out by Tonelli. ${ }^{7,8}$

In this paper, we will report a detailed ${ }^{13} \mathrm{C}$
NMR analysis of the peak arising from the isolated ethylene units in $\left[1,2-{ }^{13} \mathrm{C}\right]$ enriched E-P copolymer prepared with syndiospecific catalyst. Especially, for example, use of $\left[1,2-{ }^{13} \mathrm{C}\right]$ enriched ethylene made it possible to distinguish among meso - meso, $B_{1}$, meso $\vdash$ racemo, $B_{2}$ and racemo $\dashv$ racemo, $B_{3}$ sequences in structure $B$ from change in the NMR spectral pattern depending on the relative magnitude between the ${ }^{13} \mathrm{C}-{ }^{13} \mathrm{C}$ coupling constant and chemical shift difference.

\section{EXPERIMENTAL}

\section{Materials}

The samples of E-P or $\left[1,2-{ }^{13} \mathrm{C}\right] \mathrm{E}-\mathrm{P}$ copolymers were prepared in the presence of the catalyst systems $\mathrm{V}(\mathrm{acac})_{3} / \mathrm{Al}\left(\mathrm{C}_{2} \mathrm{H}_{5}\right)_{2} \mathrm{Cl}^{6}$ and $\mathrm{TiCl}_{3} / \mathrm{Al}\left(\mathrm{C}_{2} \mathrm{H}_{5}\right)_{2} \mathrm{Cl}$ as summarized in Table I. $\left[1,2-{ }^{13} \mathrm{C}\right]$ ethylene $(90 \%$ enrichment $)$ was pur-

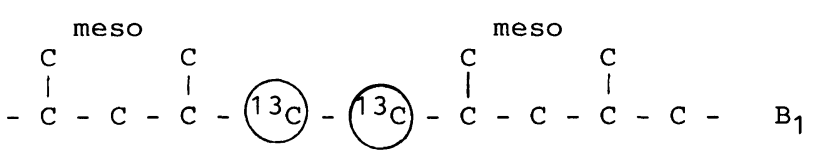
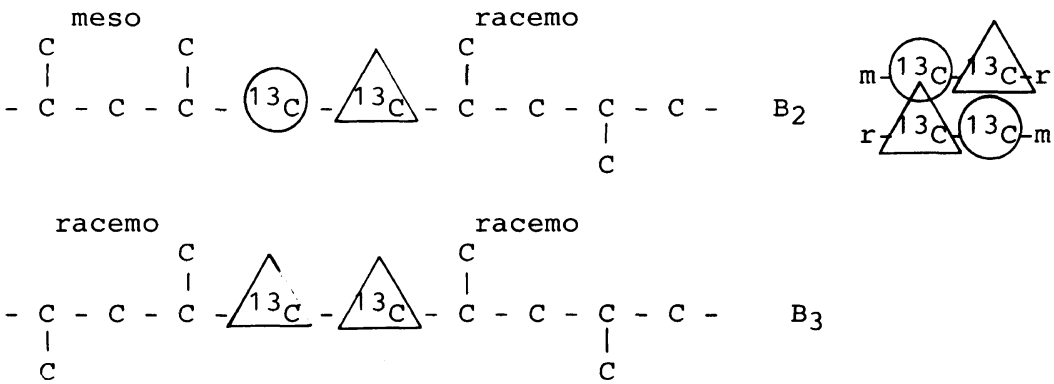
Table I. Polymerization conditions for several kinds of E-P copolymers ${ }^{\mathrm{a}}$

\begin{tabular}{|c|c|c|c|c|c|c|}
\hline & Sample No. & Catalyst system & Polymerization time/h & Time $/ \mathrm{h}^{\mathrm{b}}$ & $\begin{array}{l}\text { Ethylene content } \\
\text { in } \mathrm{mol} \%\end{array}$ & $10^{-4} \times \bar{M}_{n}^{\mathrm{c}}$ \\
\hline 1 & {$\left[1,2-{ }^{13} \mathrm{C}\right] \mathrm{E}-\mathrm{P}$} & $\mathrm{V}(\mathrm{acac})_{3} / \mathrm{Al}\left(\mathrm{C}_{2} \mathrm{H}_{5}\right)_{2} \mathrm{Cl}$ & 2.0 & 0 & 0.9 & \\
\hline 2 & {$\left[1,2-{ }^{13} \mathrm{C}\right] \mathrm{E}-\mathrm{P}$} & $\mathrm{V}(\mathrm{acac})_{3} / \mathrm{Al}\left(\mathrm{C}_{2} \mathrm{H}_{5}\right)_{2} \mathrm{Cl}$ & 2.0 & 1.0 & 0.8 & 1.2 \\
\hline 3 & {$\left[1,2-{ }^{13} \mathrm{C}\right] \mathrm{E}-\mathrm{P}$} & $\mathrm{V}(\mathrm{acac})_{3} / \mathrm{Al}\left(\mathrm{C}_{2} \mathrm{H}_{5}\right)_{2} \mathrm{Cl}$ & 2.0 & 1.8 & 0.3 & \\
\hline 4 & $\mathrm{E}-\mathrm{P}$ & $\mathrm{V}(\mathrm{acac})_{3} / \mathrm{Al}\left(\mathrm{C}_{2} \mathrm{H}_{5}\right)_{2} \mathrm{Cl}$ & 1.0 & 0 & 12 & 1.3 \\
\hline 5 & E-P & $\mathrm{V}(\mathrm{acac})_{3} / \mathrm{Al}\left(\mathrm{C}_{2} \mathrm{H}_{5}\right)_{2} \mathrm{Cl}$ & 1.0 & 0.5 & 12 & 1.4 \\
\hline 6 & {$\left[1,2-{ }^{13} \mathrm{C}\right] \mathrm{E}-\mathrm{P}$} & $\mathrm{TiCl}_{3} / \mathrm{Al}\left(\mathrm{C}_{2} \mathrm{H}_{5}\right)_{2} \mathrm{Cl}$ & 2.0 & 1.0 & 0.3 & \\
\hline
\end{tabular}

a Polymerization conditions for samples $1-5: \mathrm{V}(\mathrm{acac})_{3}=0.5 \mathrm{mmol}, \mathrm{Al}\left(\mathrm{C}_{2} \mathrm{H}_{5}\right)_{2} \mathrm{Cl}=5.0 \mathrm{mmol}$, propylene $=830 \mathrm{mmol}$, $\left[1,2-{ }^{13} \mathrm{C}\right]$ ethylene $=0.1 \mathrm{mmol}$ for samples 1,2 , and 3 , ethylene $=1.0 \mathrm{mmol}$ for samples 4 and 5 , toluene $=25 \mathrm{~cm}^{3}$, $-78^{\circ} \mathrm{C}$. For sample $6, \mathrm{TiCl}_{3}=1.5 \mathrm{mmol}, \mathrm{Al}\left(\mathrm{C}_{2} \mathrm{H}_{5}\right)_{2} \mathrm{Cl}=6.0 \mathrm{mmol}$, propylene pressure $=760 \mathrm{Torr},\left[1,2-^{13} \mathrm{C}\right]$ ethylene $=0.1 \mathrm{mmol}, 41^{\circ} \mathrm{C}$.

b Time of ethylene addition after the start of polymerization.

c Determined by GPC.

chased from Merck, Co.

\section{${ }^{13}$ C NMR Measurements}

The polymer solution was prepared at a concentration of $10 \mathrm{w} / \mathrm{v} \%$ in $o$-dichlorobenzene-deuteriobenzene $(9: 1(\mathrm{v} / \mathrm{v}))$ mixture. $^{9}$ The complete ${ }^{1} \mathrm{H}$ decoupled and INEPT (Insensitive Nuclei Enhancement by Polarization Transfer) and INADEQUATE (Incredible Natural Abundance Double Quantum Transfer Experiment). ${ }^{13} \mathrm{C}$ NMR spectra were measured at $100^{\circ} \mathrm{C}$ using JEOL FX-900 and FX200 spectrometers operating at 22.5 and $50 \mathrm{MHz}$, respectively. Only the $\mathrm{CH}$ peaks of the sample were obtained from the INEPT $(\Delta=$ $2 / 4 J$, where $J$ is the ${ }^{1} \mathrm{H}^{-13} \mathrm{C}$ direct spin-spin coupling constant) spectrum. Each $22.5 \mathrm{MHz}$ spectrum was recorded with a $4000-\mathrm{Hz}$ spectral width, $8 \mathrm{~K}$ data points and 18000 double precision accumulation. The chemical shifts were recorded in ppm with respect to an internal tetramethylsilane standard.

\section{RESULTS AND DISCUSSION}

\section{${ }^{13}$ C NMR Spectra of $\left[1,2-{ }^{13} C\right]$ Ethylene- Propylene Copolymer}

Figure 1 shows ${ }^{13} \mathrm{C}$ NMR spectra of E-P copolymer $5(22.5 \mathrm{MHz}),\left[1,2-{ }^{13} \mathrm{C}\right] \mathrm{E}-\mathrm{P}$ copolymer 1 (22.5 and $50 \mathrm{MHz}$ ) prepared with syndiotactic-specific catalyst, and $\left[1,2-{ }^{13} \mathrm{C}\right]$ E-P copolymer $6(50 \mathrm{MHz})$ prepared with isotactic-specific catalyst. The INADEQUATE spectrum of $\left[1,2-{ }^{13} \mathrm{C}\right] \mathrm{E}-\mathrm{P}$ copolymer $1(22.5 \mathrm{MHz})$ is also shown. The ${ }^{13} \mathrm{C}$ NMR spectra of samples 1 and 2 are similar and the spectra of samples 4 and 5 are also similar. Thus, ${ }^{13} \mathrm{C}$ NMR spectra of samples 2 and 5 are not shown. The ${ }^{13} \mathrm{C}$ chemical shifts are summarized in Table II.

From the spectrum of sample 6, it is easily recognized that the structure $A$ occurs exclusively in the sample prepared with isotacticspecific catalyst because the strong peaks attributable to the $S_{\alpha \gamma}$ and $S_{\beta \beta}$ carbons are observed. Here, tertiary and secondary carbons are denoted as $\mathrm{T}$ and $\mathrm{S}$, respectively, with two Greek subscripts indicating the positions relative to the nearest tertiary carbon in both directions along the polymer chain, as used by Carman et al. ${ }^{10}$ Each primary carbon is designated by $P$ with Greek subscripts defined as those of the tertiary carbons. In contrast to this case, the structure B occurs in preference to the structure $A$ in the samples prepared in the presence of syndiotactic-specific catalyst (the spectra of samples 1 and 5) because the strong peaks attributable to the $S_{\alpha \beta}$ carbons are observed. This is the same conclusion reached by Zambelli et al. ${ }^{4}$ 

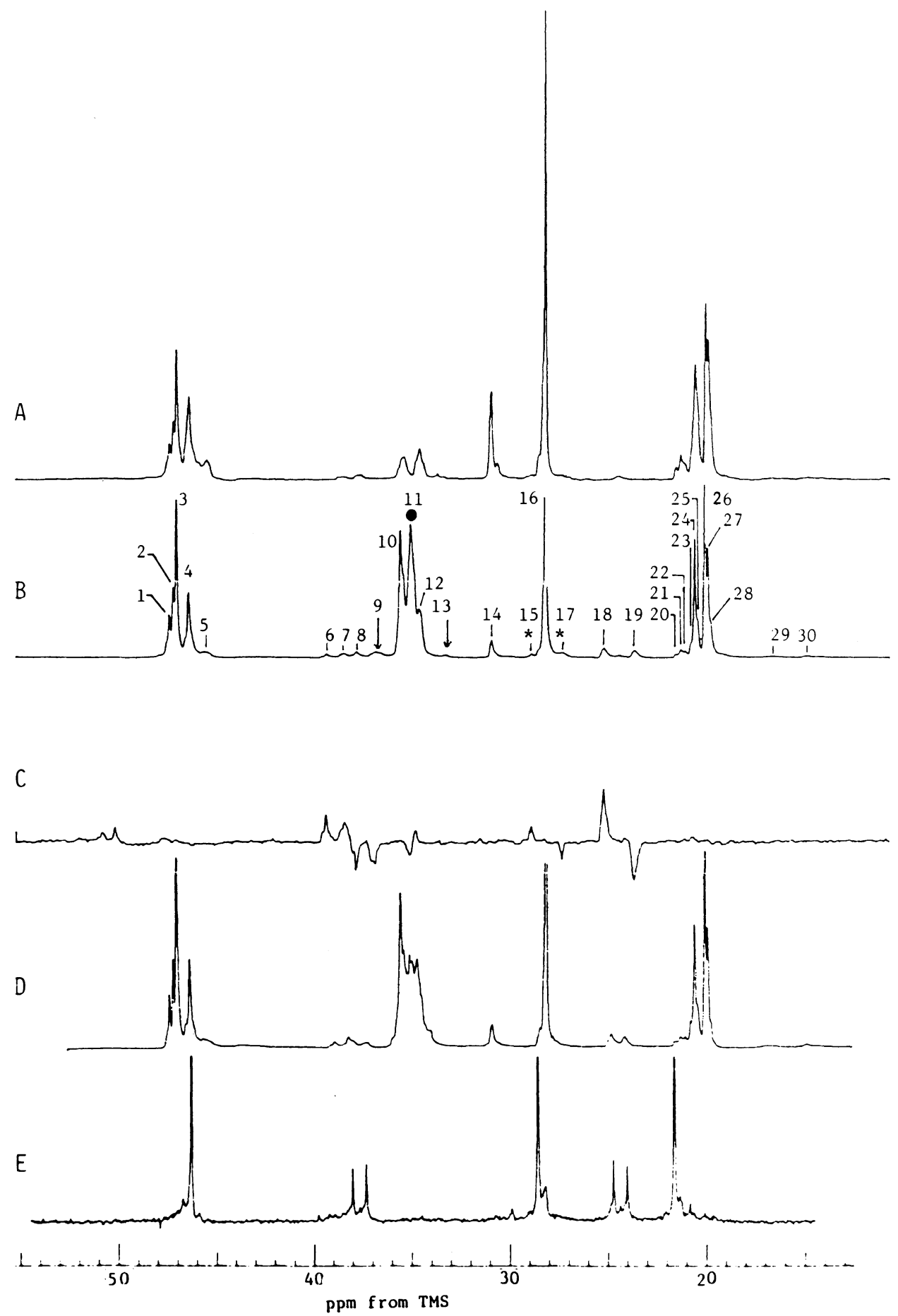

Figure 1. ${ }^{13} \mathrm{C}$ NMR spectra of E-P copolymer $5(22.5 \mathrm{MHz}) ; \mathrm{A},\left[1,2-{ }^{13} \mathrm{C}\right] \mathrm{E}-\mathrm{P}$ copolymer $1(22.5 \mathrm{MHz})$; B, $\left[1,2-{ }^{13} \mathrm{C}\right]$ E-P copolymer $1(50 \mathrm{MHz}) ; \mathrm{D}$, and $\left[1,2-{ }^{13} \mathrm{C}\right] \mathrm{E}-\mathrm{P}$ copolymer $6(50 \mathrm{MHz}), \mathrm{E}$. The INADEQUATE spectrum of sample $1, \mathrm{C}$, is also shown. 
Table II. ${ }^{13} \mathrm{C}$ NMR chemical shift ${ }^{\mathrm{a}}$ of $\left[1,2-{ }^{13} \mathrm{C}\right] \mathrm{E}-\mathrm{P}$ copolymer 1 (Spectrum B in Figure 1). The peak number was the same as in Figure 1.

\begin{tabular}{|c|c|c|}
\hline \multirow{2}{*}{$\begin{array}{l}\text { Peak } \\
\text { No. }\end{array}$} & \multirow{2}{*}{$\frac{\text { Chemical shift }}{\mathrm{ppm}}$} & \multirow{2}{*}{ Assignment } \\
\hline & & \\
\hline 1 & 47.46 & $r r m r r$ \\
\hline 2 & 47.24 & rrrrm \\
\hline 3 & 47.07 & $r r r r$ \\
\hline 4 & 46.42 & rrrmr \\
\hline 5 & $45.59-45.77$ & $\mathrm{mrm}$ \\
\hline 6 & $39.48-39.70$ & $\mathbf{S}_{\alpha \gamma} \square^{\mathbf{b}}$ \\
\hline 7 & $38.57-38.75$ & $\left.\mathrm{~S}_{\alpha \gamma}\right]^{\mathrm{b}}$ \\
\hline 8 & $37.97-38.14$ & $\mathrm{~S}_{\alpha \gamma}+$ \\
\hline 9 & $36.75-37.23$ & $+\mathrm{S}_{\alpha \beta} \downarrow$ \\
\hline 10 & 35.64 & $\left(r_{1}-\mathbf{S}_{j \alpha \beta \delta}\right)^{\mathrm{c}}$ \\
\hline 11 & 35.15 & 0 \\
\hline 12 & 34.72 & $\left(m_{1}-\mathrm{S}_{\gamma \alpha \beta \delta}\right)^{\mathrm{c}}$ \\
\hline 13 & 33.5 & $\mathrm{~S}_{\alpha \beta} \downarrow$ \\
\hline 14 & 31.03 & $\mathrm{~T}_{\beta \beta}$ \\
\hline 15 & $29.04-29.17$ & $\left.\mathrm{~T}_{\beta \beta}\right]^{\mathrm{b} *}$ \\
\hline 16 & 28.30 & \begin{tabular}{l|l}
$\mathrm{T}_{\beta \beta}$ & $r r r m+r r m r+r r r r$
\end{tabular} \\
\hline 17 & $27.48-27.69$ & $\left.\mathrm{~T}_{\beta \beta}\right]_{\mathrm{b} *}$ \\
\hline 18 & 25.35 & $\left.\mathrm{~S}_{\beta \beta}\right]^{\mathrm{b}}$ \\
\hline 19 & 23.79 & $\left.\mathrm{~S}_{\beta \beta}\right]$ \\
\hline 20 & 21.76 & $m m m m$ \\
\hline 21 & 21.45 & $m m m r$ \\
\hline 22 & 21.24 & $r m m r$ \\
\hline 23 & 20.93 & $m m r r$ \\
\hline 24 & 20.76 & $r r m r$ \\
\hline 25 & 20.59 & $m r m r$ \\
\hline 26 & 20.24 & $r r r$ \\
\hline 27 & 20.11 & $\mathrm{rrrm}$ \\
\hline 28 & 19.94 & mrrm \\
\hline 29 & $16.82-17.21$ & $\left(m_{0}-\mathbf{P}_{\alpha \beta}\right)^{\mathrm{c}}$ \\
\hline 30 & $15.08-15.26$ & $\left(r_{0}-\mathrm{P}_{\alpha \beta}\right)^{\mathrm{c}}$ \\
\hline
\end{tabular}

a In ppm from TMS.

b ${ }^{13} \mathrm{C}-{ }^{13} \mathrm{C}$ spin coupled.

c Detailed assignment is shown in ref 11 .

Each methylene peak, $\mathrm{S}_{\alpha \gamma}$ and $\mathrm{S}_{\beta \beta}$, of sample 1 splits into a doublet, which is due to ${ }^{13} \mathrm{C}-{ }^{13} \mathrm{C}$ spin coupling of $\left[1,2-{ }^{13} \mathrm{C}\right]$ ethylene unit as can be seen from the INADEQUATE spectrum and also from a comparison of the 22.5 and $50 \mathrm{MHz}$ spectra of sample 1 . The small peaks with asterisk observed on both sides of the main methine peak are also due to ${ }^{13} \mathrm{C}-{ }^{13} \mathrm{C}$ spin coupling of non-enriched ${ }^{13} \mathrm{C}$ nuclei.

\section{Analysis of $S_{\alpha \beta}$ Resonance}

The methylene carbon, $S_{\alpha \beta}$ peak located at the tail-to-tail sequence of polypropylene splits roughly into two peaks with a peak separation of about $1 \mathrm{ppm}\left(\mathrm{C}^{*}\right.$ peak in structure $\left.\mathrm{B}\right)$. The lower field peak was assigned to $r-S_{\alpha \beta}, \triangle$, and the higher field one to $m-S_{\alpha \beta}, \bigcirc$, (structures $B_{1}-B_{3}$ ) as reported previously. ${ }^{4,11,12}$

The same assignment is also applicable to the peak $S_{\alpha \beta}$ observed in the spectrum of sample 4. However, we cannot tell whether the $m-\mathrm{S}_{\alpha \beta}{ }^{13} \mathrm{C}$ nuclei, $O$, are in the structures $\mathrm{B}_{1}$ or $\mathrm{B}_{2}$ and also whether the $r-\mathrm{S}_{\alpha \beta}{ }^{13} \mathrm{C}$ nuclei, $\triangle$, are in the structures $B_{2}$ or $B_{3}$. In order to overcome the problem, we tried to use [1,2${ }^{13} \mathrm{C}$ ] ethylene in the preparation of the E-P copolymer. Taking into account the values of both the ${ }^{13} \mathrm{C}-{ }^{13} \mathrm{C}$ spin coupling constant and the chemical shift difference of the two peaks, $m-\mathrm{S}_{\alpha \beta}$ and $r-\mathrm{S}_{\alpha \beta}$, the appearance of $\mathrm{AB}$ spin system is expected in the structure $B_{2}$ and thus, it is possible to distinguish the structure $\mathrm{B}_{2}$ from structures $B_{1}$ and $B_{3}$ in the ${ }^{13} C$ NMR spectrum. This prediction is proved as follows.

The most interesting spectral character is the appearance of a new peak, between $m$ - and $r-\mathrm{S}_{\alpha \beta}$ peaks in the spectrum of the $\left[1,2-{ }^{13} \mathrm{C}\right]$ E-P copolymer, which is noticed by a comparison of the spectra of samples 5 and 1 . The spectral pattern of the $S_{\alpha \beta}$ peaks is clearly different between 22.5 and $50 \mathrm{MHz}$, especially the shape of the new peak,

The methine peak, $T_{\alpha \beta}$ located at the headto-head sequence of polypropylene is expected to appear in the same resonance region. ${ }^{12,13}$ However, as shown in Figure 2, the INEPT $2 / 4 J\left(J={ }^{1} \mathrm{H}-{ }^{13} \mathrm{C}\right.$ direct spin coupling constant in $\mathrm{Hz}$ ) spectrum which gives only methine peak, indicates that the new peak 0 is not assigned to the methine carbon, $\mathrm{T}_{\alpha \beta}$.

The $S_{\alpha \beta}$ peak is expanded in Figure 3 together with the assignment. Thus, the new peak and also small new peaks marked by arrows show $A B$ spin system (the ${ }^{13} \mathrm{C}-{ }^{13} \mathrm{C}$ spin coupling constant and chemical shift difference are 35.1 and 18.2 in $\mathrm{Hz}$, respectively) and are attributable to the $S_{\alpha \beta}$ carbon in the structure $B_{2}$. From peak simulation of 
T. Asakura et al.

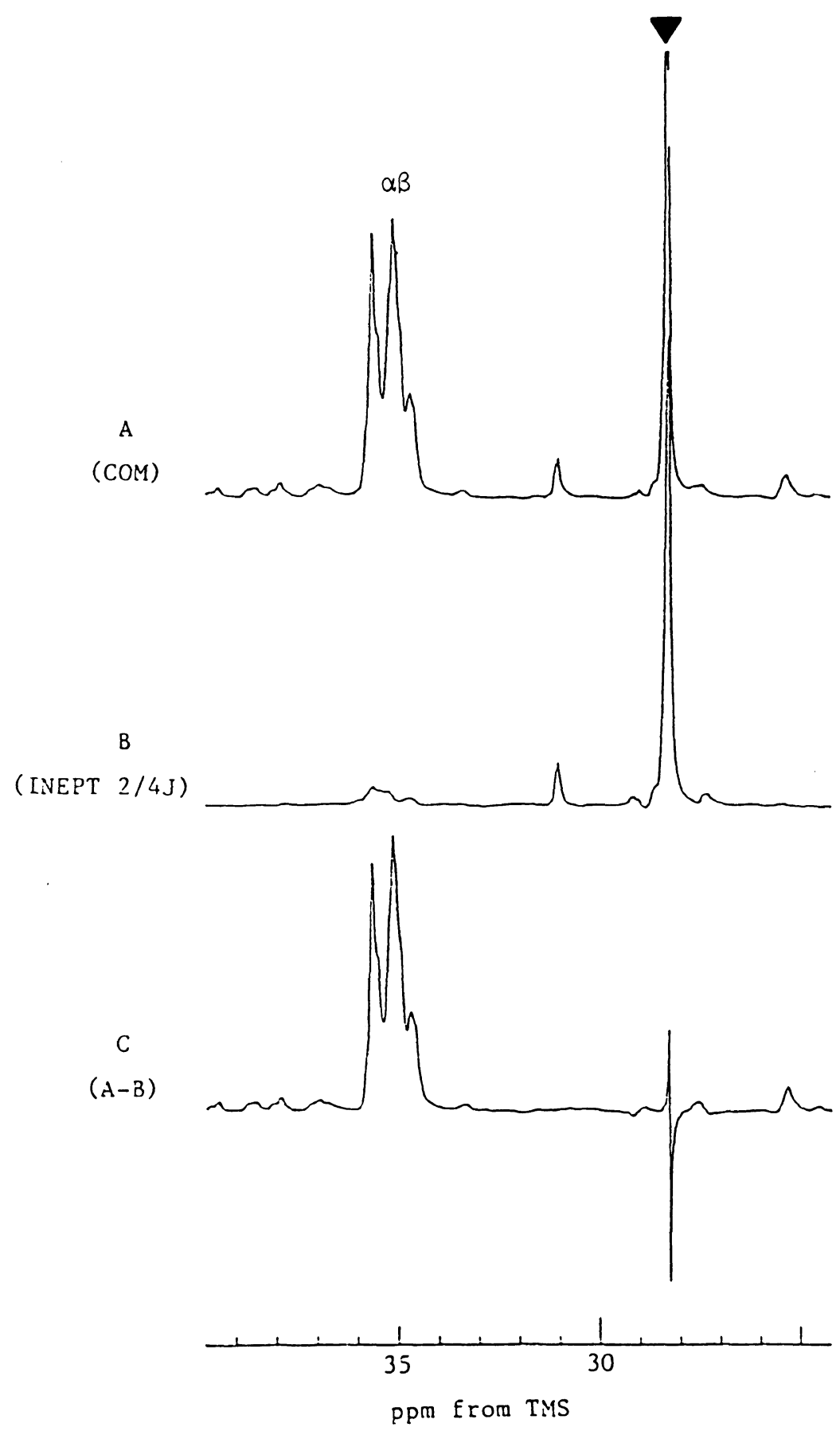

Figure 2. ${ }^{13} \mathrm{C}$ NMR spectra of the $\mathrm{S}_{\alpha \beta}$ resonance regions of $\left[1,2-{ }^{13} \mathrm{C}\right] \mathrm{E}-\mathrm{P}$ copolymer 1 . A, COM; B, INEPT $(\Delta=2 / 4 J)$, C, difference $(\mathrm{A}-\mathrm{B}) ; \boldsymbol{\nabla}$, reference peak, $\mathrm{T}_{\alpha \beta}$. 

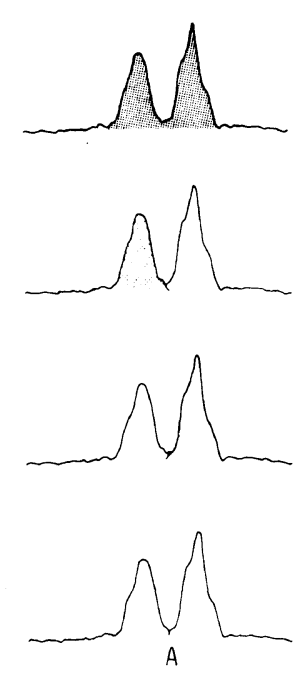
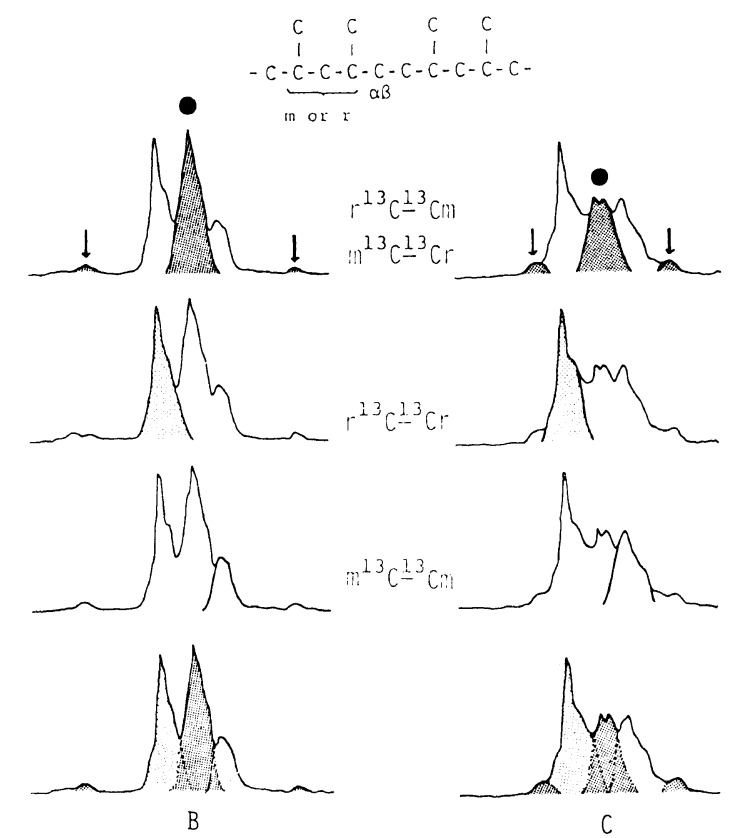

Figure 3. ${ }^{13} \mathrm{C}$ NMR analysis of $\mathrm{S}_{\alpha \beta}$ resonance regions of $\mathrm{E}-\mathrm{P}$ copolymers. A, sample $5 ; \mathrm{B},\left[1,2-{ }^{13} \mathrm{C}\right] \mathrm{E}-\mathrm{P}$ copolymer $1(22.5 \mathrm{MHz})$; C, $\left[1,2-{ }^{13} \mathrm{C}\right] \mathrm{E}-\mathrm{P}$ copolymer $1(50 \mathrm{MHz})$.

the $\mathrm{S}_{\alpha \beta}$ resonance region, the fractions of structures, $\mathrm{B}_{1}, \mathrm{~B}_{2}$, and $\mathrm{B}_{3}$ were determined as $0.10,0.55$, and 0.35 , respectively.

Next, we will examine whether or not the same stereochemistry is maintained when the isolated $\left[1,2-{ }^{13} \mathrm{C}\right]$ ethylene is inserted during the propagation of $\left[1,2-{ }^{13} \mathrm{C}\right] \mathrm{E}-\mathrm{P}$ copolymer chain. In the preparation of samples 1,2 , and $3,\left[1,2-{ }^{13} \mathrm{C}\right]$ ethylene was added in the starting, middle and final stages of the living polymerization of propene with the $\mathrm{V}(\mathrm{acac})_{3} /$ $\mathrm{Al}\left(\mathrm{C}_{2} \mathrm{H}_{5}\right)_{2} \mathrm{Cl}$ catalyst, ${ }^{6}$ respectively. Figure 4 shows the $\mathrm{S}_{\alpha \gamma}, \mathrm{S}_{\alpha \beta}$, and $\mathrm{S}_{\beta \beta}$ peaks together with the methine peaks. The spectra of samples 1 and 2 are quite similar to each other, but the spectrum of sample 3 is slightly different from these two spectra; the methylene peaks originated from $\left[1,2-{ }^{13} \mathrm{C}\right]$ ethylene are small. This indicates that a part of the ethylene are not inserted into PP in the preparation of sample 3. The ${ }^{13} \mathrm{C}$ NMR spin lattice relaxation times, $T_{1}$ of these $\left[1,2-{ }^{13} \mathrm{C}\right] \mathrm{E}-\mathrm{P}$ copolymers, 1, 2, and 3 observed at $40^{\circ} \mathrm{C}(50 \mathrm{MHz})$ are summarized
Table III. Spin-lattice relaxation times, ${ }^{\mathrm{a}} T_{1}$ of every carbon in $\left[1,2-{ }^{13} \mathrm{C}\right] \mathrm{E}-\mathrm{P}$ copolymers 1,2 , and 3 observed at $40^{\circ} \mathrm{C}(50 \mathrm{MHz})$

\begin{tabular}{lllcc}
\hline & & 1 & 2 & 3 \\
\hline $\mathrm{S}_{\alpha \alpha}$ & rrmrr & 0.21 & 0.22 & 0.16 \\
$\mathrm{~S}_{\alpha \alpha}$ & rrrrm & 0.20 & 0.22 & 0.17 \\
$\mathrm{~S}_{\alpha \alpha}$ & rrrrr & 0.18 & 0.19 & 0.17 \\
$\mathrm{~S}_{\alpha \alpha}$ & rrrmr & 0.21 & 0.23 & 0.16 \\
$\mathrm{~S}_{\alpha \beta}{ }^{b}$ & & 0.26 & 0.29 & 0.24 \\
$\mathrm{~T}_{\beta \beta}$ & & 0.32 & 0.32 & 0.31 \\
$\mathrm{P}_{\beta \beta}$ & rrmrrr & 0.67 & 0.69 & 0.62 \\
$\mathrm{P}_{\beta \beta}$ & rrrrm & 0.58 & 0.53 & 0.57 \\
$\mathrm{P}_{\beta \beta}$ & rrrrr & 0.65 & 0.66 & 0.63 \\
$\mathrm{P}_{\beta \beta}$ & rrrrmr & 0.72 & 0.74 & 0.66 \\
\hline
\end{tabular}

a In $\mathrm{s}$.

b Averaged over the individual peaks of $S_{\alpha \beta}$.

in Table III. ${ }^{9,14,15}$ The $T_{1}$ values of methylene, methine, and methyl carbons of the PP sequence and also those of the $S_{\alpha \beta}$ carbons are similar among samples 1,2 , and 3 , indicating that the local dynamics of the $S_{\alpha \beta}$ carbons in the chain are the same among these samples. 
T. Asakura et al.
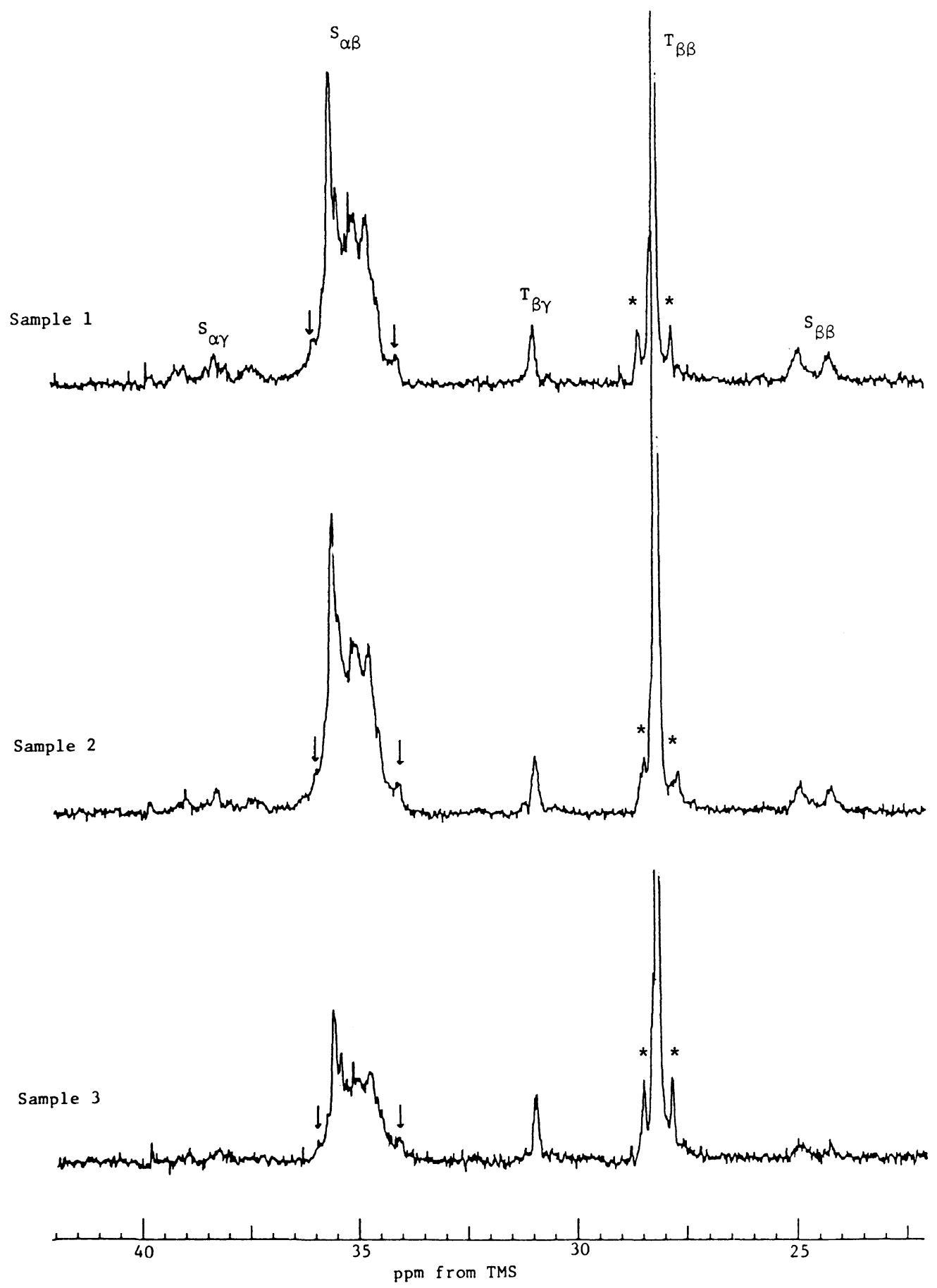

Figure 4. ${ }^{13} \mathrm{C}$ NMR spectra of $\left[1,2-{ }^{13} \mathrm{C}\right] \mathrm{E}-\mathrm{P}$ copolymers, samples 1,2 , and $3(23-42 \mathrm{ppm})$. 
The ratios of the peak intensities, $\mathrm{S}_{\alpha \beta} / \mathrm{S}_{\beta \beta}$ were similar among these samples being 13.4, 13.6, and 13.0 for samples, 1, 2, and 3, respectively. In addition, the shapes of the $S_{\alpha \beta}$ region are essentially the same among these spectra. These data lead to the conclusion that the olefin polymerization mechanism of syndiotactic-specific catalyst is essentially the same during the propagation.

\section{REFERENCES}

1. A. Zambelli, G. Gatti, C. Sacchi, W. O. Crain, and J. D. Roberts, Macromolecules, 4, 475 (1971).

2. A. Zambelli, "NMR, Basic Principles and Progress," Vol. 4, O. Diehl, E. Fluck, and O. Kosfeld, Ed., Springer-Verlag, New York, N. Y., 1971.

3. J. M. Sanders and R. A. Komoroski, Macromolecules, 10, 1214 (1977).
4. A. Zambelli, G. Bajo, and E. Rigamonti, Makromol. Chem., 179, 1249 (1978).

5. A. Zambelli, M. C. Sacchi, and P. Locatelli, Macromolecules, 12, 783 (1979).

6. Y. Doi, T. Koyama, K. Soga, and T. Asakura, Makromol. Chem., 185, 1827 (1984).

7. A. E. Tonelli, Macromolecules, 11, 634 (1978).

8. A. E. Tonelli, Macromolecules, 12, 255 (1979).

9. T. Asakura and Y. Doi, Macromolecules, 16, 786 (1983).

10. C. J. Carman, R. A. Harrington, and C. E. Wilkes, Macromolecules, 10, 536 (1977).

11. H. N. Cheng, Macromolecules, 17, 1950 (1984).

12. T. Asakura, Y. Nishiyama, and Y. Doi, Macromolecules, 20, 616 (1987).

13. T. Asakura, I. Ando, A. Nishioka, Y. Doi, and T. Keii, Makromol. Chem., 178, 791 (1977).

14. T. Asakura and Y. Doi, Macromolecules, 13, 454 (1980).

15. T. Asakura and Y. Doi, Macromolecules, 14, 72 (1981). 